\title{
Condensed-phase nitric acid in a tropical subvisible cirrus cloud
}

\author{
P. J. Popp, ${ }^{1,2}$ T. P. Marcy, ${ }^{1,2}$ L. A. Watts, ${ }^{1,2}$ R. S. Gao, ${ }^{1}$ D. W. Fahey, ${ }^{1}$ E. M. Weinstock, ${ }^{3}$ \\ J. B. Smith, ${ }^{3}$ R. L. Herman, ${ }^{4}$ R. F. Troy, ${ }^{4}$ C. R. Webster, ${ }^{4}$ L. E. Christensen, ${ }^{4}$ \\ D. G. Baumgardner, ${ }^{5}$ C. Voigt, ${ }^{6}$ B. Kärcher, ${ }^{6}$ J. C. Wilson, ${ }^{7}$ M. J. Mahoney, ${ }^{4}$ E. J. Jensen, ${ }^{8}$ \\ and T. P. Bui ${ }^{8}$
}

Received 27 August 2007; revised 9 November 2007; accepted 28 November 2007; published 28 December 2007.

[1] In situ observations in a tropical subvisible cirrus cloud during the Costa Rica Aura Validation Experiment on 2 February 2006 show the presence of condensed-phase nitric acid. The cloud was observed near the tropopause at altitudes of $16.3-17.7 \mathrm{~km}$ in an extremely cold (183$191 \mathrm{~K})$ and dry $\left(<5 \mathrm{ppm} \mathrm{H}_{2} \mathrm{O}\right)$ air mass. Relative humidities with respect to ice ranged from $150-250 \%$ throughout most of the cloud. Optical particle measurements indicate the presence of ice crystals as large as $90 \mu \mathrm{m}$ in diameter. Condensed $\mathrm{HNO}_{3} / \mathrm{H}_{2} \mathrm{O}$ molar ratios observed in the cloud particles were 1-2 orders of magnitude greater than ratios observed previously in cirrus clouds at similar $\mathrm{HNO}_{3}$ partial pressures. Nitric acid trihydrate saturation ratios were 10 or greater during much of the cloud encounter, indicating that $\mathrm{HNO}_{3}$ may be present in the cloud particles as a stable condensate and not simply physically adsorbed on or trapped in the particles. Citation: Popp, P. J., et al. (2007), Condensed-phase nitric acid in a tropical subvisible cirrus cloud, Geophys. Res. Lett., 34, L24812, doi:10.1029/2007GL031832.

\section{Introduction}

[2] Subvisible cirrus clouds that form near the tropical tropopause represent an uncertain though potentially significant component in Earth's radiation budget [McFarquhar et al., 2000]. Subvisible cirrus also represent the last opportunity for the removal of water vapor from air entering the stratosphere in the tropics [Jensen et al., 1996]. Owing to the high altitudes and remote locations of subvisible cirrus in the tropics, however, comprehensive in situ observations of these clouds have been limited [Peter et al., 2003]. While cirrus ice particles are known to be effective scavengers of nitric acid $\left(\mathrm{HNO}_{3}\right)$ under a range of conditions [Voigt et al., 2007], previous measurements in subvisible cirrus over the

\footnotetext{
${ }^{1}$ Chemical Sciences Division, NOAA Earth System Research Laboratory, Boulder, Colorado, USA.

${ }^{2}$ Cooperative Institute for Research in Environmental Sciences, University of Colorado, Boulder, Colorado, USA

${ }^{3}$ Atmospheric Research Project, Harvard University, Cambridge, Massachusetts, USA.

${ }^{4}$ Jet Propulsion Laboratory, California Institute of Technology, Pasadena, California, USA.

${ }^{5}$ Centro de Ciencias de la Atmosfera, Universidad Nacional Autónoma de México, Mexico City, Mexico.

${ }^{6}$ Institut für Physik der Atmosphäre, Deutsches Zentrum für Luft- und Raumfahrt, Oberpfaffenhofen, Germany.

${ }^{7}$ Department of Engineering, University of Denver, Denver, Colorado, USA.

${ }^{8}$ NASA Ames Research Center, Moffett Field, California, USA.
}

Copyright 2007 by the American Geophysical Union. 0094-8276/07/2007GL031832\$05.00 western Indian Ocean revealed no evidence of $\mathrm{HNO}_{3}$ condensed with the ice particles [Luo et al., 2003].

[3] We report here observations of condensed-phase $\mathrm{HNO}_{3}$ in a tropical subvisible cirrus cloud at high relative humidities with respect to ice $(150-250 \%$ throughout most of the cloud). These measurements were conducted onboard the NASA WB-57F high-altitude research aircraft as part of the Costa Rica Aura Validation Experiment (CR-AVE). The data are used here to assess the uptake of $\mathrm{HNO}_{3}$ in subvisible cirrus particles and explore the role of nitric acid trihydrate (NAT) formation in the uptake process.

\section{Observations}

[4] Condensed-phase $\mathrm{HNO}_{3}$ was detected in situ with the NOAA chemical ionization mass spectrometer (CIMS) located in the third pallet position of the WB-57F aircraft. The NOAA CIMS methodology for sampling condensedphase $\mathrm{HNO}_{3}$ in cirrus clouds has been described in detail elsewhere [Popp et al., 2004]. Briefly, the instrument measures $\mathrm{HNO}_{3}$ with two independent channels of detection connected to separate forward- and downward-facing inlets. The forward-facing inlet samples both gas- and particlephase $\mathrm{HNO}_{3}$. Particles larger than $\sim 1 \mu \mathrm{m}$ in diameter are inertially stripped from the airstream sampled by the downward-facing inlet, effectively yielding a measure of gasphase $\mathrm{HNO}_{3}$. The difference in the signal between the two channels and knowledge of the particle sampling efficiency of the forward-facing inlet allows a determination of the amount of $\mathrm{HNO}_{3}$ in the condensed phase.

[5] Condensed-phase $\mathrm{HNO}_{3}$ was observed coincident with a subvisible cirrus cloud on the southbound leg of a WB-57F science flight over the eastern Pacific Ocean on 2 February 2006. The cloud was observed over a geographic extent of approximately $800 \mathrm{~km}$, at latitudes between $7^{\circ} \mathrm{N}$ and the equator. This flight originated and terminated at Juan Santamaria International Airport in San Jose, Costa Rica $\left(10^{\circ} \mathrm{N}, 84^{\circ} \mathrm{W}\right)$. The cloud described here was observed visually by the WB-57F flight crew, but only when viewed horizontally with a long optical path. A real-time display of ice particle number density in the WB-57F cockpit, measured with an optical particle counter, was used to determine a range of flight altitudes to perform porpoising maneuvers through the cloud (Figure 1d). Time series data of $\mathrm{HNO}_{3}$ mixing ratios observed from the forward and downward CIMS channels are shown in Figure 1a. The presence of condensed-phase $\mathrm{HNO}_{3}$ is indicated by a significant difference in the $\mathrm{HNO}_{3}$ mixing ratio observed in the forward and downward CIMS channels (pink highlighted region in Figure 1). The presence of cirrus ice particles is indicated 


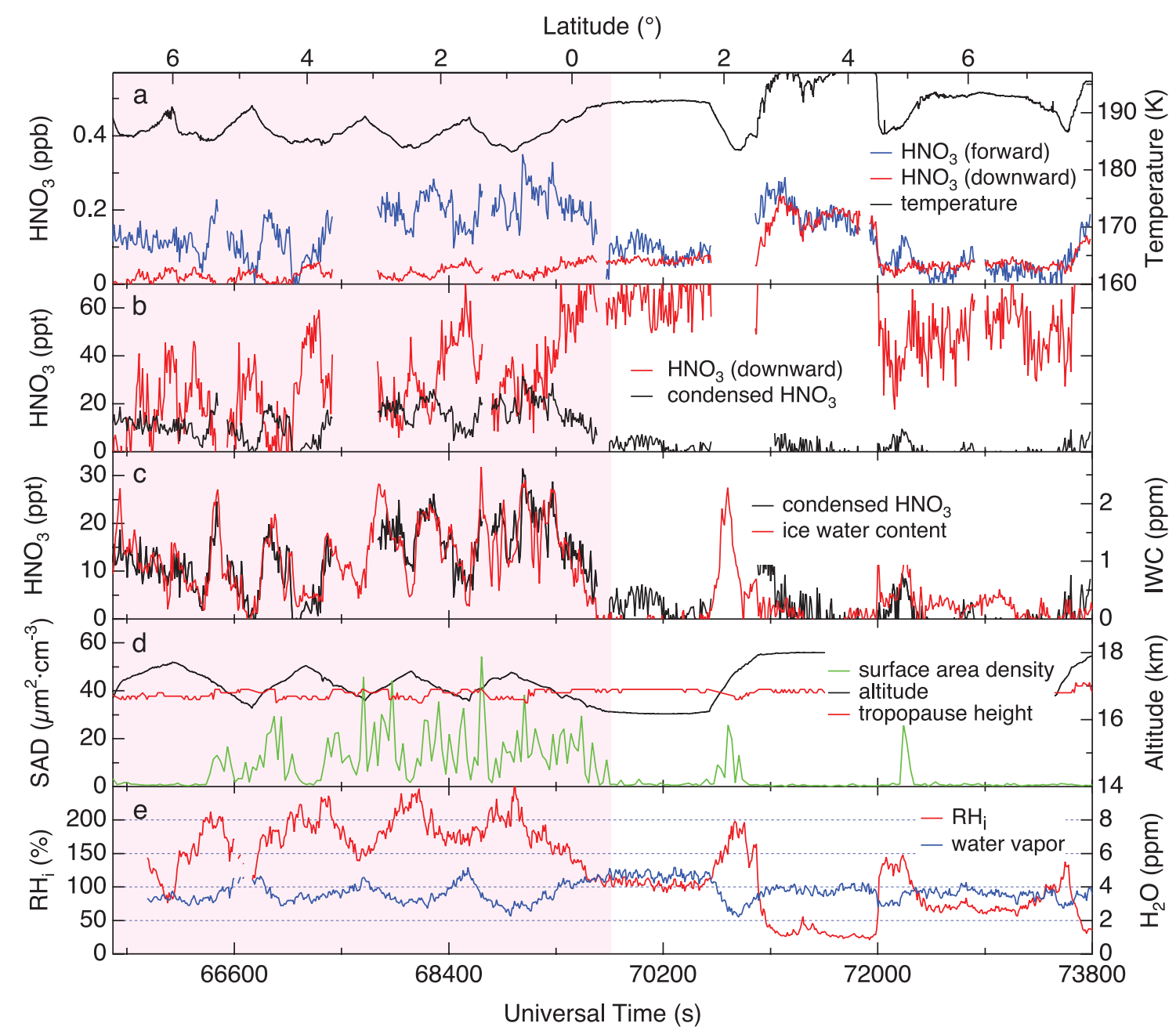

Figure 1. Time series measurements of $\mathrm{HNO}_{3}$ mixing ratio observed from the forward and downward CIMS channels on the flight of 2 February 2006. The subvisible cirrus cloud was observed in the pink highlighted region. Also shown are ambient temperature [Scott et al., 1990], condensed $\mathrm{HNO}_{3}$, IWC (calculated as the difference between total water and water vapor [Webster et al., 1994; May, 1998]), SAD [Baumgardner et al., 2001], flight altitude, tropopause height [Denning et al., 1989], water vapor [Weinstock et al., 1994], and relative humidity. (a, b, c) Note the change in the $\mathrm{HNO}_{3}$ scale.

by enhancements in ice water content (IWC) and surface area density (SAD) above background values (Figures 1c and 1d).

[6] The subvisible cirrus cloud was observed at flight altitudes of approximately $16.3-17.7 \mathrm{~km}$. Microwave temperature profiles indicate that the cirrus layer was observed at or slightly higher than the lapse-rate tropopause (Figure 1d). The cold-point tropopause during the cloud encounter occurred approximately $500 \mathrm{~m}$ higher than the lapse-rate tropopause, but still within the cloud. Ambient temperatures in this region ranged from 183-191 K (Figure 1a). These low temperatures and ambient water vapor values of 2.3-5.2 ppm correspond to relative humidities with respect to ice of $150-250 \%$ throughout most of the cloud (Figure 1e). Measurements in subvisible cirrus during at least one other CR-AVE flight revealed similarly high relative humidities [Jensen et al., 2007]. Gas-phase $\mathrm{HNO}_{3}$ mixing ratios observed near the tropical tropopause were less than 100 ppt. Despite these low values, the low ambient temperatures caused nitric acid trihydrate (NAT) saturation ratios to be 10 or greater during much of the cloud encounter [Hanson and Mauersberger, 1988].

[7] Condensed-phase $\mathrm{HNO}_{3}$ values, calculated by accounting for the particle sampling efficiency of the CIMS instrument [Popp et al., 2004], exceeded 30 ppt during the cloud encounter (Figures $1 \mathrm{~b}$ and 1c). Ice water content shows a strong temporal correlation with condensed-phase $\mathrm{HNO}_{3}$ in the cloud (Figure 1c), consistent with previous measurements in convectively formed subtropical cirrus clouds [Popp et al., 2004]. Measurements in the convective cirrus also showed a strong correlation between condensedphase $\mathrm{HNO}_{3}$ and ice particle SAD. Ice particle SADs are derived by integrating particle size distribution and number density measurements from the Cloud, Aerosol, and Precipitation Spectrometer (CAPS) assuming quasi-spherical particles in this size range [Baumgardner et al., 2001]. Ice particle SADs in the cloud were typically less than $50 \mu \mathrm{m}^{2}$. $\mathrm{cm}^{-3}$ (Figure 1d), which is in strong contrast to SADs of up to $6 \cdot 10^{5} \mu \mathrm{m}^{2} \cdot \mathrm{cm}^{-3}$ observed in the convectively-formed cirrus [Popp et al., 2004]. We note that the SAD values observed at the beginning of the cloud encounter 


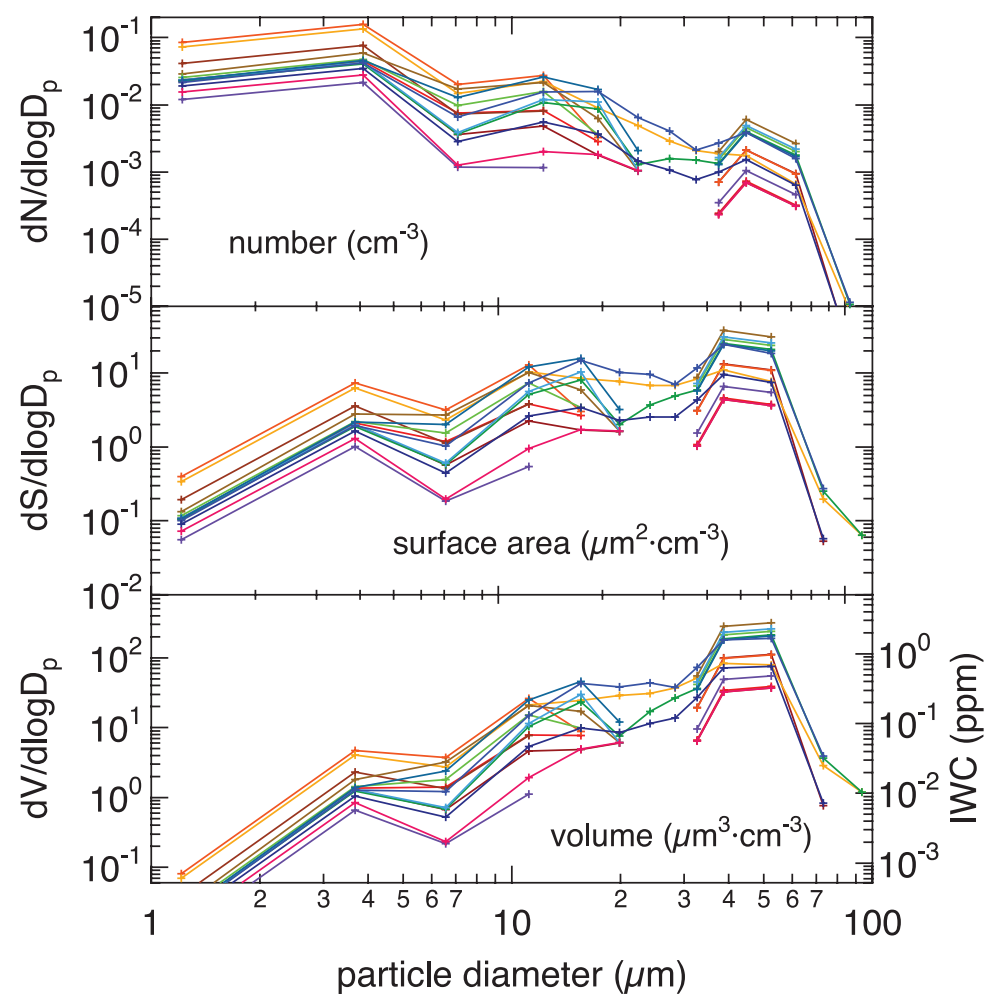

Figure 2. Particle number, surface area, and volume density distributions measured in the subvisible cirrus. Data are shown as 5-minute averages throughout the cloud.

$(<66600$ UT, Figure 1d) are lower than expected, given the enhanced values of IWC and condensed-phase $\mathrm{HNO}_{3}$ observed during the same time period (Figure 1c).

[8] Ice particle size distributions reported by the CAPS instrument show the presence of large ice crystals (30$90 \mu \mathrm{m}$ diameter) in the cloud, as well as a smaller particle mode at $10-20 \mu \mathrm{m}$ (Figure 2). The size distributions also indicate that the ice particle surface area and volume density, and therefore ice water content, are dominated by the large-particle mode. An ice particle growth model [Jensen et al., 2007] indicates that growth times for the largest particles shown in Figure $2(90 \mu \mathrm{m})$ are $\sim 3-4$ hours under conditions observed in the subvisible cirrus cloud. Smaller particles $(30 \mu \mathrm{m})$ have growth times less than one hour.

\section{Discussion}

[9] We assume that the sampled particles are composed primarily of ice, with a small molar fraction of $\mathrm{HNO}_{3}$ contained in the bulk of the particle [Kärcher and Voigt, 2006]. The data reported here suggest the observed condensed-phase $\mathrm{HNO}_{3}$ does not exist as a separate population of NAT particles or STS aerosol. First, condensed-phase $\mathrm{HNO}_{3}$ exhibits a strong temporal correlation with ice water content in the cloud and was only observed in the presence of cirrus particles, as indicated by enhancements in both ice water content and ice particle surface area density (Figure 1). Second, a population of STS aerosols cannot grow to sizes large enough to produce the differential response shown by the CIMS instrument in Figure 1a. Particles smaller than approximately $1 \mu \mathrm{m}$ in diameter are neither enhanced in the forward-facing CIMS inlet nor inertially stripped from the airstream sampled by the downward-facing inlet. Finally, maximum values of ice water content observed in the cloud ( $2.5 \mathrm{ppm}$, Figure 1c) can be accounted for by the large $(30-90 \mu \mathrm{m})$ ice particle mode observed by the CAPS instrument (Figure 2).

[10] Results from the Aerosol Inorganics Model (AIM) [Carslaw et al., 1995] indicate that, under ambient conditions typical for the observed cloud (with ice formation inhibited in the model run to simulate ice supersaturation), gas-phase $\mathrm{HNO}_{3}$ will be depleted at temperatures less than approximately $191 \mathrm{~K}$ should NAT form (Figure 3). The model also indicates that the background sulfate aerosol can take up a substantial fraction of the available $\mathrm{HNO}_{3}$ at temperatures less than approximately $188 \mathrm{~K}$, resulting in the production of a supercooled ternary solution (STS) of water, sulfuric acid and $\mathrm{HNO}_{3}$. At temperatures less than $186 \mathrm{~K}$, essentially all of the ambient $\mathrm{HNO}_{3}$ can be partitioned into the STS phase. We note, however, that the AIM describes $\mathrm{HNO}_{3}$ partitioning under equilibrium conditions and does not account for the uptake of $\mathrm{HNO}_{3}$ by cirrus ice crystals. The observations reported here indicate that $\mathrm{HNO}_{3}$ partitions into the ice phase when present, sometimes completely, despite the fact that NAT or STS aerosols are also thermodynamically stable. These results are consistent with numerical simulations of a polar cirrus cloud that indicate $\mathrm{HNO}_{3}$ will be driven from the liquid aerosol and incorporated in cirrus particles as soon as ice forms [Kärcher, 2005].

[11] Microphysical modeling studies together with in situ observations provide evidence that $\mathrm{HNO}_{3}$ can be trapped and subsequently buried in growing ice particles under 


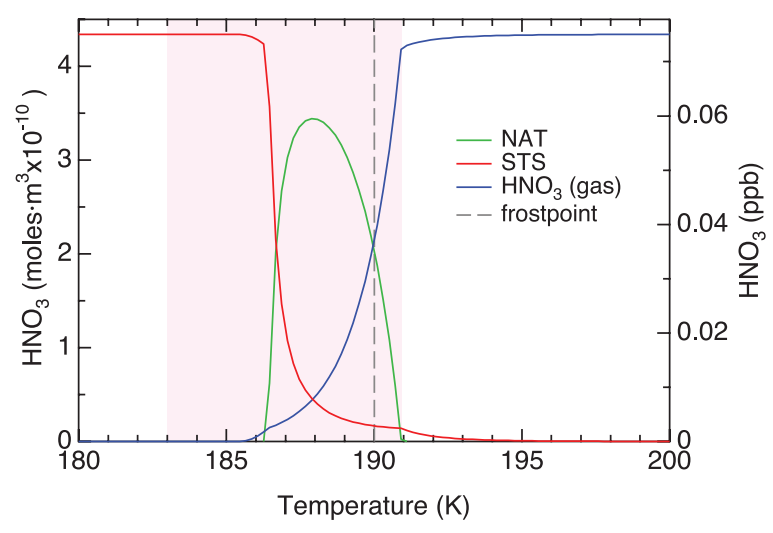

Figure 3. $\mathrm{HNO}_{3}$ partitioning in the tropical lower stratosphere calculated by the Aerosol Inorganics Model (AIM). Model inputs, typical of conditions observed in the subvisible cirrus cloud, were 75 ppt $\mathrm{HNO}_{3}, 3.5$ ppm $\mathrm{H}_{2} \mathrm{O}$, and $0.25 \mathrm{ppbm} \mathrm{H}_{2} \mathrm{SO}_{4}$ [Wilson et al., 1992]. The temperature range observed in the subvisible cirrus is shown by the region highlighted in pink.

conditions typical of the tropical tropopause [Kärcher and Voigt, 2006; Voigt et al., 2006; Voigt et al., 2007]. The trapping process is fundamentally controlled by the $\mathrm{HNO}_{3}$ residence time on the ice surface and the particle growth rate [Kärcher and Basko, 2004]. As a result, the efficiency of the trapping process increases with decreasing temperature and increasing relative humidity. The $\mathrm{HNO}_{3}$ content in cirrus particles can be expressed as the condensed $\mathrm{HNO}_{3} / \mathrm{H}_{2} \mathrm{O}$ molar ratio [Voigt et al., 2006]. The observed $\mathrm{HNO}_{3} / \mathrm{H}_{2} \mathrm{O}$ ratios in the subvisible cirrus reported here are 1-2 orders of magnitude greater than ratios previously observed in cirrus clouds at similar $\mathrm{HNO}_{3}$ partial pressures (Figure 4). It's reasonable to speculate that these high ratios result from the low temperatures $(183-191 \mathrm{~K})$ and the associated high $\mathrm{RH}_{\mathrm{i}}$ values $(150-250 \%)$ in the cloud. Under such conditions, trapping theory predicts that the maximum condensed $\mathrm{HNO}_{3} / \mathrm{H}_{2} \mathrm{O}$ ratio in a cirrus particle is approximately one quarter of the ambient gas-phase $\mathrm{HNO}_{3} / \mathrm{H}_{2} \mathrm{O}$ ratio [Kärcher and Voigt, 2006]. This limitation of less than unity is due to the effective gas phase diffusion coefficients of $\mathrm{HNO}_{3}$ and $\mathrm{H}_{2} \mathrm{O}$. Since the mean condensed $\mathrm{HNO}_{3} / \mathrm{H}_{2} \mathrm{O}$ ratio reported here $\left(1.4 \cdot 10^{-5}\right.$, Figure 4$)$ is $\sim 0.25$ times the ambient $\mathrm{HNO}_{3} / \mathrm{H}_{2} \mathrm{O}$ ratio at higher altitudes $(\sim 18 \mathrm{~km})$ where these particles nucleate (Figure 1, $71100 \mathrm{UT}$ ), these results indicate very efficient trapping of $\mathrm{HNO}_{3}$ in the observed cloud. These observations are consistent with laboratory measurements that reveal enhanced and long-term $\mathrm{HNO}_{3}$ uptake on growing ice films at $\mathrm{RH}_{\mathrm{i}}$ values greater than $100 \%$ (compared to static ice films), indicative of the trapping of $\mathrm{HNO}_{3}$ in the film [Ullerstam and Abbatt, 2005]. It is also worth noting that the $\mathrm{HNO}_{3}$ dissolved in ice at equilibrium, extrapolated from laboratory measurements at higher temperatures and $\mathrm{HNO}_{3}$ partial pressures [Thibert and Dominé, 1998], is approximately an order of magnitude too low to produce the condensed $\mathrm{HNO}_{3} / \mathrm{H}_{2} \mathrm{O}$ molar ratios in the cloud reported here (Figure 4). We conclude, therefore, that the condensed $\mathrm{HNO}_{3}$ we observe is truly trapped in the particle and not simply dissolved in the ice.
[12] Water vapor was measured with multiple instruments onboard the WB-57F during CR-AVE. Recently, the accuracy of water vapor measurements at low mixing ratios has been under careful scrutiny because significant differences have been reported between various instruments during previous measurement campaigns. The water vapor data shown in Figure 1 are provided by the Harvard Water Vapor (HWV) instrument using a Lyman- $\alpha$ fluorescence detection scheme [Weinstock et al., 1994]. The reported accuracy of the HWV instrument was $\pm 15 \%$ at water vapor mixing ratios less than $10 \mathrm{ppm}$ during the flight on 2 February 2006. While there was no significant difference between the HWV and Integrated Cavity Output Spectroscopy (ICOS) instruments [Sayres, 2006] during this flight (data not shown), the ICOS measurements were $\sim 0.5 \mathrm{ppm}$ lower than the HWV measurements on at least one other CR-AVE flight [Jensen et al., 2007]. The reported accuracy for the ICOS instrument is $\pm 5 \%$, with a potential bias of $0.25 \mathrm{ppm}$. Thus, a difference of $0.5 \mathrm{ppm}$ does not represent a significant discrepancy between the two instruments. At the low water vapor mixing ratios observed in the subvisible cirrus cloud, a difference in water vapor of $0.5 \mathrm{ppm}$ represents a decrease of approximately $25 \%$ in the calculated $\mathrm{RH}_{\mathrm{i}}$. We conclude, therefore, that water vapor is highly supersaturated throughout most of the cloud $\left(\mathrm{RH}_{\mathrm{i}}\right.$ of at least $125-$ $225 \%$ ) regardless of the water vapor measurement chosen for this analysis.

[13] Finally, we note that the cloud described here was highly supersaturated with respect to NAT. Measurements in contrail cirrus at temperatures less than $\mathrm{T}_{\mathrm{NAT}}$ have fueled speculation that $\mathrm{HNO}_{3}$ serves to increase the relative humidity with respect to ice in low-temperature cirrus clouds via the formation of NAT-like hydrates on the particle surface [Gao et al., 2003]. With the simultaneous observation of condensed-phase $\mathrm{HNO}_{3}$ and high relative humidities in the cloud reported here, it seems reasonable to speculate that $\mathrm{HNO}_{3}$ uptake by subvisible cirrus particles might play an important role in the water vapor budget near the tropopause [Gao et al., 2003]. It is also worth noting

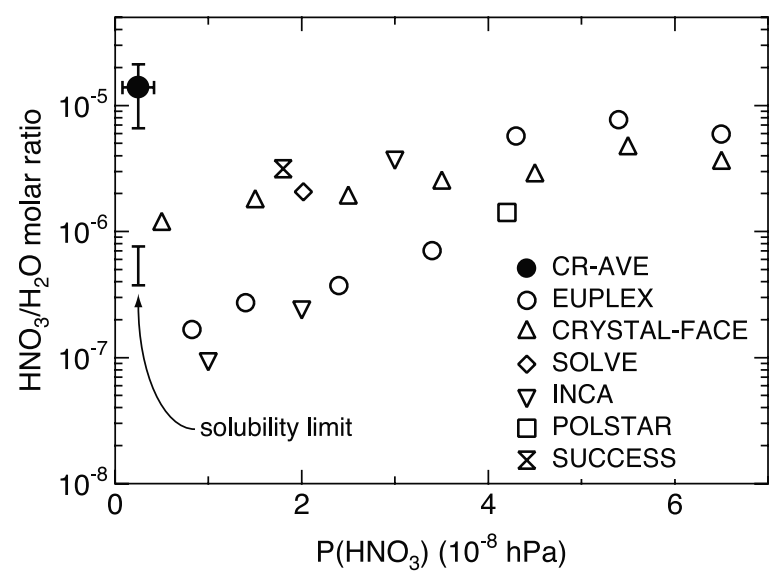

Figure 4. Relationship between the $\mathrm{HNO}_{3} / \mathrm{H}_{2} \mathrm{O}$ molar ratio in cirrus particles and the $\mathrm{HNO}_{3}$ partial pressure in the cloud from various airborne field campaigns. All data except CR-AVE taken from Voigt et al. [2006]. The solubility limit of $\mathrm{HNO}_{3}$ in ice is shown for the range of temperatures observed in the cloud $(183-191 \mathrm{~K})$. 
that NAT formation on the particle surface is likely to increase the $\mathrm{HNO}_{3}$ residence time on the particle (i.e. decrease the rate of escape from the surface) and further enhance the $\mathrm{HNO}_{3}$ trapping process [Kärcher and Voigt, 2006].

[14] Acknowledgments. The authors wish to thank the air and ground crews of the NASA WB-57F aircraft. Access to the online Aerosol Inorganics Model by S. L. Clegg, P. Brimblecombe, and A. S. Wexler at http://www.aim.env.uea.ac.uk/aim/aim.html is greatly appreciated. This work was partially supported by the NASA Upper Atmospheric Research Program and NOAA Atmospheric Chemistry and Climate Program. Work performed at the Jet Propulsion Laboratory, California Institute of Technology, was done under contract with NASA.

\section{References}

Baumgardner, D., et al. (2001), The cloud, aerosol and precipitation spectrometer: A new instrument for cloud investigations, Atmos. Res., 59-60, $251-264$.

Carslaw, K. S., S. L. Clegg, and P. Brimblecombe (1995), A thermodynamic model for the system of $\mathrm{HCl}-\mathrm{HNO}_{3}-\mathrm{H}_{2} \mathrm{SO}_{4}-\mathrm{H}_{2} \mathrm{O}$, including solubilities of $\mathrm{HBr}$, from $<200 \mathrm{~K}$ to $328 \mathrm{~K}$, J. Phys. Chem., 99, $11,557-11,574$

Denning, R. F., S. L. Guidero, G. S. Parks, and B. L. Gary (1989), Instrument description of the Airborne Microwave Temperature Profiler, J. Geophys. Res., 94, 16,757-16,765.

Gao, R. S., et al. (2003), Evidence that ambient nitric acid increases relative humidity in low-temperature cirrus clouds, Science, 303, 516-520.

Hanson, D., and K. Mauersberger (1988), Laboratory studies of the nitric acid trihydrate: Implications for the South polar stratosphere, Geophys. Res. Lett., 15, 855-858, doi:10.1029/88GL00209.

Jensen, E. J., O. B. Toon, L. Pfister, and H. B. Selkirk (1996), Dehydration of the upper troposphere and lower stratosphere by subvisible cirrus clouds near the tropical tropopause, Geophys. Res. Lett., 23, 825-828, doi:10.1029/96GL00722.

Jensen, E. J., et al. (2007), Formation of large $(\sim 100 \mu \mathrm{m})$ ice crystals near the tropical tropopause, Atmos. Chem. Phys. Discuss., 7, 6293-6327.

Kärcher, B. (2005), Supersaturation, dehydration and denitrification in Arctic cirrus, Atmos. Chem. Phys., 5, 1757-1772.

Kärcher, B., and M. M. Basko (2004), Trapping of trace gases in growing ice crystals, J. Geophys. Res., 109, D22204, doi:10.1029/2004JD005254.

Kärcher, B., and C. Voigt (2006), Formation of nitric acid/water ice particles in cirrus clouds, Geophys. Res. Lett., 33, L08806, doi:10.1029/ 2006 GL025927.

Luo, B. P., et al. (2003), Dehydration potential of ultrathin clouds at the tropical tropopause, Geophys. Res. Lett., 30(11), 1557, doi:10.1029/ 2002GL016737.

May, R. D. (1998), Open-path, near-infrared tunable diode laser spectrometer for atmospheric measurements of $\mathrm{H}_{2} \mathrm{O}, J$. Geophys. Res., 103(D15), 19,161-19,172.
McFarquhar, G. M., et al. (2000), Thin and subvisual tropopause tropical cirrus: Observations and radiative impacts, J. Atmos. Sci., 57, 18411853.

Peter, T., et al. (2003), Ultrathin Tropical Tropopause Clouds (UTTCs): I. Cloud morphology and occurrence, Atmos. Chem. Phys. 3, 1083-1091.

Popp, P. J., et al. (2004), Nitric acid uptake on subtropical cirrus cloud particles, J. Geophys. Res., 109, D06302, doi:10.1029/2003JD004255.

Sayres, D. S. (2006), New techniques for accurate measurement of water and water isotopes, Ph.D. thesis, Harvard Univ., Cambridge, Mass.

Scott, S. G., et al. (1990), The meteorological measurement system on the NASA ER-2 aircraft, J. Atmos. Oceanic Technol., 7, 525-540.

Thibert, E., and F. Dominé (1998), Thermodynamics and kinetics of the solid solution of $\mathrm{HNO}_{3}$ in ice, J. Phys. Chem. B, 102, 4432-4439, doi:10.1021/jp980569.

Ullerstam, M., and J. P. D. Abbatt (2005), Burial of gas-phase $\mathrm{HNO}_{3}$ by growing ice surfaces under tropospheric conditions, Phys. Chem. Chem. Phys., 7, 3596-3600.

Voigt, C., H. Schlager, H. Ziereis, B. Kärcher, B. P. Luo, C. Schiller, M. Krämer, P. J. Popp, H. Irie, and Y. Kondo (2006), Nitric acid in cirrus clouds, Geophys. Res. Lett., 33, L05803, doi:10.1029/2005GL025159.

Voigt, C., et al. (2007), In situ observations and modeling of small nitric acid-containing ice crystals, Atmos. Chem. Phys., 7, 3373-3383.

Webster, C. R., et al. (1994), Aircraft (ER-2) laser infrared absorption spectrometer (ALIAS) for in-situ stratospheric measurements of $\mathrm{HCl}$ $\mathrm{N}_{2} \mathrm{O}, \mathrm{CH}_{4}, \mathrm{NO}_{2}$, and $\mathrm{HNO}_{3}$, Appl. Opt., 33, 454-472.

Weinstock, E. M., et al. (1994), New fast-response photofragment fluorescence hygrometer for use on the NASA ER-2 and the Perseus remotely piloted aircraft, Rev. Sci. Instrum., 65, 3544-3554.

Wilson, J. C., M. R. Stolzenburg, W. E. Clark, M. Loewenstein, G. V. Ferry, K. R. Chan, and K. K. Kelly (1992), Stratospheric sulfate aerosol in and near the Northern Hemisphere polar vortex: The morphology of the sulfate layer, multimodal size distributions, and the effect of denitrification, J. Geophys. Res., 97(D8), 7997-8013.

D. G. Baumgardner, Centro de Ciencias de la Atmosfera, Universidad Nacional Autónoma de México, Circuito Exterior s/n, Cuidad Universitaria, Mexico City, Mexico City D. F. 04150, México.

T. P. Bui and E. J. Jensen, NASA Ames Research Center, Moffett Field, CA 94035, USA.

L. E. Christensen, R. L. Herman, M. J. Mahoney, R. F. Troy, and C. R. Webster, Jet Propulsion Laboratory, California Institute of Technology, Pasadena, CA 91109, USA.

D. W. Fahey, R. S. Gao, T. P. Marcy, P. J. Popp, and L. A. Watts, Chemical Sciences Division, NOAA Earth System Research Laboratory, 325 Broadway R/AL6, Boulder, CO 80305, USA. (peter.j.popp@noaa.gov)

B. Kärcher and C. Voigt, Institut für Physik der Atmosphäre, Deutsches Zentrum für Luft- und Raumfahrt, Oberpfaffenhofen, Postfach 1116, D82230 Wessling, Germany.

J. B. Smith and E. M. Weinstock, Atmospheric Research Project, Harvard University, Cambridge, MA 02138, USA.

J. C. Wilson, Department of Engineering, University of Denver, Denver, CO 80208, USA. 